\title{
Los contratos administrativos. Una comparación entre México y Canadá (con énfasis en el régimen de Quebec) ${ }^{* * *}$
}

\section{The administrative contracts. A comparison between Mexico \& Canada (emphasis in Quebec's regime)}

\section{RESUMEN}

El objeto de este trabajo es realizar un ejercicio microcomparatista de la institución jurídica de los contratos administrativos, entre el régimen mexicano y el canadiense. Ambos sistemas jurídicos corresponden a tradiciones completamente diferentes. Mientras que la contratación administrativa en Canadá se considera parte de su common law, a pesar de la fuerte influencia del civil law -debida al sistema bijural rector por la Provincia de Quebec-, en el derecho mexicano se sigue la tradición civilista y la doctrina clásica francesa de los contratos administrativos. Sin embargo, en ambos casos existe una fuerte influencia de una tradición diferente. El objetivo del artículo es encontrar las similitudes y las diferencias en lo que en un principio sería una institución de comportamientos completamente distintos y que, sin embargo, persiguen los mismos objetivos y procuran evitar prácticas similares.

PALABRAS CLAVE

Derecho administrativo, contratos administrativos, derecho comparado, sistemas legales, common law, civil law.

Doctor en Derecho por la Universidad Panamericana, Campus México; maestro en Ciencias Jurídicas y licenciado en Derecho por el ITEso. Profesor investigador de la Universidad Panamericana, Campus México, Ciudad de México, México.Contacto: 1jbejar@up.edu.mx

Miembro del Sistema Nacional de Investigadores del CONACYT. Visiting Research Fellow de la Facultad de Derecho de la Universidad de Montreal.

*** Recibido el 11 de septiembre de 2017, aprobado el 4 de abril de 2018.

Para citar el artículo: BÉJAR RIVERA, L. J. Los contratos administrativos. Una comparación entre México y Canadá (con énfasis en el régimen de Quebec). En Revista Derecho del Estado, Universidad Externado de Colombia. N. ${ }^{\circ}$ 42, enero-abril de 2019, pp. 51-82.

DoI: https://doi.org/10.18601/01229893.n42.03 
ABSTRACT

This article pretends to be a micro comparative exercise among the legal institution of administrative contracts, between the Mexican and Canadian legal regimes. Both legal systems correspond to completely different legal traditions. While the administrative contracts in Canada are considered part of their common law, notwithstanding the strong civil law influence, due to bijural system that rules in the Province of Quebec; in Mexican law, it follows the civilist tradition and the classic French doctrine of the administrative contracts. Nevertheless, in both cases, exists a strong influence of the different tradition. So, the objective of this article is to find the similitudes and differences in what could be seen as a complete different way of behaviour of the same institution, but, searches for the same objectives and procures avoid similar practices.

KEYWORDS

Administrative Law, Administrative Contracts, Comparative Law, Legal Systems, Common Law, Civil Law.

SUMARIO

Introducción. 1. Contextualización de los contratos administrativo. 2. La adjudicación de los contratos administrativos. 3. Los tipos de contratos administrativos. 4. Las reglas de formación de los contratos. 5. Las reglas de ejecución de los contratos. 5.1. Fiscalización de contratos públicos. 5.2. Modificación de contratos administrativos. 5.3. Rescisión del contrato administrativo. 6. Globalización, derecho comparado y sistemas mixtos. Conclusiones. Referencias.

\section{INTRODUCCIÓN}

Sin duda, uno de los temas más estudiados por el derecho público en el mundo iberoamericano es el de los contratos administrativos. Infinidad de páginas se le han dedicado, para referirse a temas tan elementales (pero no por ello menos importantes) como la naturaleza jurídica de estos instrumentos, las formas de adjudicación de los contratos y las implicaciones que esto tiene para el Estado, deteniéndose en la diferencia con lo que sucede en la contratación de derecho privado.

La línea divisoria entre uno y otro contrato, de derecho público y de derecho privado, históricamente se ha identificado en la autonomía de la voluntad de las partes cuando celebran uno de naturaleza privada, y en el sometimiento a 
la legalidad cuando se trata de uno público ${ }^{1}$; sin embargo, se encuentra que dentro del contrato de carácter administrativo se vienen introduciendo, cada vez con mayor frecuencia, elementos propios de la contratación privada.

Ahora bien, en el mundo anglosajón, regido por el common law, la contratación pública no se ha diferenciado en mucho respecto de la contratación privada; sin embargo, la intervención del Estado como parte contratante supone ciertos tintes que responden (por lo menos someramente) al entendimiento de los contratos administrativos derivados de la teoría francesa.

Es en el marco de esta tesitura que se sitúa la presente investigación. Así, en la revisión del régimen de los contratos administrativos en México y Canadá, se tratará de encontrar sus similitudes y diferencias, lo que hará posible conocer de mejor manera el desenvolvimiento de la misma institución jurídica en dos sistemas legales en principio completamente diferentes. Este análisis conducirá a concluir, sin embargo, que los resultados son similares, aun cuando se hayan tomado caminos distintos para llegar a ellos.

En pocas palabras, el confrontar la misma institución jurídica, una dentro los de los sistemas civilistas y la otra dentro del common law, hará posible identificar de manera precisa el comportamiento de dicha institución, y sobre todo, apreciar los puntos de conexión y de influencia mutua de los dos sistemas.

La contratación pública hoy en día, sin importar a cuál familia o tradición jurídica corresponda, tiene exactamente los mismos objetivos, es decir, asegurarse del correcto uso de los recursos públicos, de tal forma que, tanto en un sistema altamente reglado como el mexicano -que sigue los modelos latinoamericanos- como, por otra parte, en un sistema poco reglado (y con incidencias regladas) como el canadiense, es posible ver claramente que la institución de la contratación pública es perfectamente homologable. Institución respecto de la cual, incluso, en el diálogo entre civil law y common law -como lo demuestra el caso de Quebec con el gobierno nacional canadiense-, es posible encontrar situaciones muy similares, problemáticas comunes $\mathrm{y}$, por ende, soluciones también comunes, a pesar de la diversidad de los caminos, de tal forma que ambos sistemas pueden aprender mucho el uno del otro.

Lo anterior cobra aún mayor relevancia si se considera que en el actual entorno globalizado resulta indispensable que existan este tipo de mecanismos de diálogo y tráfico jurídico, máxime en el caso de México y Canadá, que forman parte del -tan discutido en los últimos tiempos- Tratado de Libre Comercio de América del Norte (TLCAN), donde el tráfico comercial entre ambos países incluye también negocios en el ámbito de la contratación pública.

Así las cosas, el objetivo final de este trabajo es comprobar que la institución de los contratos administrativos no es una institución estática sino que,

1 En el presente trabajo se utilizan como sinónimos las expresiones "contrato público", "contrato administrativo" y "contrato estatal", sin que ello implique que no se reconocen las posibles diferencias que pudieran tener y sobre las cuales se han elaborado múltiples trabajos. 
por el contrario, está en constante movimiento. En principio, este dinamismo se debe a una evolución natural, que se ve acrecentado por la globalización, en la que las instituciones se van transformando y adaptando, conociendo incluso trasplantes de otros sistemas jurídicos.

El desarrollo de esta aportación parte de mostrar las similitudes que ambos modelos, mexicano y canadiense, guardan en relación con la contratación pública, en cuanto a su regulación general; así como también algunos puntos relacionados con los llamados contratos energéticos en México. Esto permitirá mostrar la influencia que el derecho mexicano ha recibido de los sistemas de common law y la manera como se ha intentado realizar trasplantes de estos al sistema jurídico mexicano.

Con ello, lo que se pretende es demostrar que, efectivamente, un sistema mixto en la contratación administrativa puede funcionar (más allá de lo perfectible que pueda resultar en varios casos) si se tienen claras las reglas que aplican, si los modelos son el resultado de un cuidadoso estudioso sobre la conveniencia de ciertas prácticas y, por supuesto, si se facilita este nuevo tráfico jurídico global.

\section{CONTEXTUALIZACIÓN DE LOS CONTRATOS ADMINISTRATIVOS}

Previo al análisis de las diferencias y similitudes entre los contratos administrativos en el derecho canadiense y mexicano, es necesario presentar brevemente el estado de la cuestión.

En el caso mexicano, la contratación administrativa ha tenido un trayecto (por decir lo menos) bastante accidentado. Es importante recordar que desde la época de la Colonia ya se tenía una especie de regulación sobre las concesiones, principalmente mineras y bancarias, aun cuando su conceptualización como contrato o como acto especial, por lo menos en el caso mexicano, depende de la época a la cual se haga referencia ${ }^{2}$.

Sin embargo, no es necesario ir tan atrás en el tiempo para poder determinar el camino que ha seguido la institución del contrato administrativo, bastando con señalar que, como dice Galindo Camacho, "[e]n México, hasta principios de la década de los cincuentas, los contratos que consideramos como administrativos eran considerados contratos regidos por el derecho privado"3.

Desde la segunda mitad del siglo pasado, los contratos administrativos cobraron su dimensión propia dentro del derecho público, a partir de múltiples leyes que se han ido sucediendo en el tiempo, desde la Ley de Inspección de Contratos y Obras Públicas de 1966, pasando por la Ley de Obra Pública

2 Por lo menos en el ámbito federal, la concesión se considera un acto administrativo especial, no un contrato; cfr., al respecto, SANTOFimio GamboA, J. O. y BéJar Rivera, L. J. Las concesiones públicas. Fundamentación teórica. México: Novum, 2014, 145 ss.

3 Galindo Camacho, M. Derecho administrativo II. México: Porrúa, 1996, p. 121. 
de 1980, la Ley de Adquisiciones, Arrendamientos y Servicios relacionados con Bienes Nacionales de 1985 y la Ley de Adquisiciones y Obras Públicas de 1993, hasta las vigentes hoy en día (con sus diversas reformas): la Ley de Obras Públicas y Servicios Relacionados con las Mismas (LOPSRM), la Ley de Adquisiciones, Arrendamientos y Servicios del Sector Público (LAASSP) y la Ley de Asociaciones Público Privadas (LAPP), como parte del gran marco de contrataciones a nivel federal.

En el caso canadiense es preciso comprender, ante todo, el sistema jurídico tan peculiar al que están incorporados tales contratos. Canadá es un país cuyo ordenamiento jurídico se rige, en principio, por el common law, y así mismo su derecho administrativo está definido por este. En consecuencia, su desarrollo legislativo en el ámbito federal es mínimo, y en gran medida estos contratos operan de acuerdo a políticas y lineamientos establecidos en sede administrativa, muchos de los cuales están cimentados en la llamada freedom of executive action ${ }^{4}$. Por otra parte, debido a razones históricas (y sin que sea oportuno enfrentar este tema ahora), la Provincia de Quebec se ha desenvuelto bajo el modelo de civil law o tradición romano-canónica, por influencia directa del derecho francés, aunque también allí , al igual que en el ámbito nacional, se entiende al derecho administrativo como parte del common law.

De esta manera, el sistema canadiense es un sistema mixto ${ }^{5}$, aunque inclinado hacia el common law, razón por la cual aun en Quebec muchas de las disposiciones normativas existentes no hacen más que recoger los principios y la jurisprudencia propios del common law, con la particularidad de que para quienes han sido formados en la tradición romano-canónica, muchas de sus disposiciones y fallos no resultan ajenas a los principios de la contratación pública.

En términos generales, en el ámbito federal canadiense, la contratación estatal se ha regido por diversos reglamentos, dentro de los cuales se destaca el actual Règlement sur les Marchés de l'État (RME). En el caso específico de la provincia de Quebec, la cuestión se encuentra reglada por la Loi sur les Contrats de Organismes Publics (LCOP), la cual en realidad no guarda mayores diferencias con la normativa federal. Ahora bien, conviene señalar que, aun cuando estos dos no son los únicos que regulan cuestiones de la contratación estatal en Canadá, son los que se tomarán como base para el estudio de derecho comparado que se pretende hacer en este artículo.

4 Este principio encuentra su origen en el derecho británico, con el fallo en el caso Rederiaktiebolaget Amphitrite v. The King.

5 Este sistema mixto se define típicamente como "bijuralismo", referido a la coexistencia y comunicación entre ambos sistemas dentro de Canadá. Cfr. Allard, F. La Cour Suprême du Canada et son impact sur l'articulation du bijuridisme. Disponible en: http://www.justice.gc.ca/ fra/pr-rp/sjc-csj/harmonization/hlf-hfl/f3-b3/bf3a.html (Consultado el 6 de marzo de 2017). 
En cuanto al ámbito de aplicación de estas normas, es necesario aclarar que la RME se aplicará siempre y cuando la autoridad contratante corresponda al ámbito nacional y los recursos financieros deriven de la Corona ${ }^{6}$, de acuerdo a lo establecido en su artículo 3. En cambio, la LCOP se aplicará solamente para las autoridades provinciales y municipales de Quebec ${ }^{7}$. Finalmente, cuando se trate de proyectos compartidos entre el gobierno nacional y el gobierno provincial, se aplicarán ambas normas en caso de ser necesario, pues no se debe perder de vista que el derecho administrativo canadiense (incluido el de Quebec) corresponde al common law, y por tanto existe bastante flexibilidad en cuanto a la aplicación directa de normas.

Es importante destacar que en Canadá se ha seguido muy de cerca la misma tendencia del derecho administrativo británico, de tal forma que no resulta extraño que muchas de las temáticas y preocupaciones para su estudio tengan origen en el derecho británico. Así, a partir del fenómeno privatizador que se ha vivido en todo el mundo ${ }^{8}$ (tanto en los sistemas de common law como en los sistemas de tradición civilista), en materias propias de los servicios públicos (electricidad, agua potable, transporte, etc.) se ha dejado cada vez más en manos de los particulares en el entorno de tradición civilista, a partir de la concesión, y en otros sistemas a partir de la contratación (no necesariamente entendida como contratos administrativos en su concepción francesa ${ }^{9}$ ); en el mundo anglosajón, tal y como señala Hunt:

Además de la privatización en su sentido más obvio, la reinvención del gobierno ha tomado una variedad de formas. Actividades que previamente estaban sometidas a un control administrativo duro, han sido desreguladas y otras actividades que anteriormente desarrollaban directamente los órganos públicos han sido "contratadas" con el sector privado. Tal vez, de forma más dramática, las técnicas de la administración pública han sido rediseñadas en el molde del sector comercial privado [...] El contrato ha remplazado a la orden y el control como paradigma de la regulación ${ }^{10}$.

$6 \quad$ No se debe perder de vista que Canadá, aun teniendo un régimen federal, también está gobernado por la Corona Británica, aunque su intervención es mínima en cuanto a la autodeterminación del pueblo canadiense.

7 Cfr. art. 4 LCOP.

8 Cfr. Greve, C. y EJersbo, N. Contracts as Reinvented Institutions in the Public Sector: Cros-Cultural Comparison. Westport: Praeger, 2005, 2 ss.

9 Este sería el caso del derecho mexicano, donde en el sector energético se ha liberalizado a partir del régimen de los contratos celebrados por el monopolio del sector público, encabezado por la Comisión Federal de Electricidad, como empresa productiva del Estado.

10 Hunt, M. Constitutionalism and the Contractualisation of Government in the United Kingdom. En TAGgart, M. (ed.), The Province of Administrative Law. Oxford: Hart Publishing, 1997, 21 (trad. libre). 
Reiterando lo que se ha venido señalando en las líneas precedentes, la regulación de los contratos administrativos, corresponde a una categoría híbrida entre el derecho público y el derecho privado. En este orden de ideas, el profesor canadiense Patrice Garant señala: "La diferencia esencial que existe en nuestro derecho entre el contrato de la empresa privada y el contrato administrativo no es una diferencia de una categoría jurídica fundamental" ", lo que muestra cómo los fundamentos jurídicos de ambos contratos son comunes.

El Código Civil de Quebec (CCQ) señala que tanto los contratos públicos como privados se rigen por las reglas relativas al Libro de obligaciones y, en concreto, el artículo 1376 ibídem señala expresamente la aplicación de dichas reglas al Estado, a sus organismos y a cualquier otra persona moral de derecho público a la que le pudiesen resultar aplicables otras reglas de derecho.

Así, tal como lo señalan McCann y Thiboutot, "[1]os contratos administrativos son de una naturaleza híbrida. Están sometidos a la vez a reglas de derecho privado, (abundantes) reglas de derecho público y a principios jurisprudenciales que se han formado por el common law de los contratos administrativos" $"$.

\section{LA ADJUDICACIÓN DE LOS CONTRATOS ADMINISTRATIVOS}

Antes de abordar el tema de la adjudicación de los contratos administrativos, como punto de partida, es importante destacar que tanto México como Canadá han asumido los compromisos internacionales en esta materia y han ratificado la Convención de la Organización de las Naciones Unidas contra la Corrupción, que dispone:

Artículo 9. Contratación pública y gestión de la hacienda pública

1. Cada Estado Parte, de conformidad con los principios fundamentales de su ordenamiento jurídico, adoptará las medidas necesarias para establecer sistemas apropiados de contratación pública, basados en la transparencia, la competencia y criterios objetivos de adopción de decisiones, que sean eficaces, entre otras cosas, para prevenir la corrupción. Esos sistemas, en cuya aplicación se podrán tener en cuenta valores mínimos apropiados, deberán abordar, entre otras cosas:

a) La difusión pública de información relativa a procedimientos de contratación pública y contratos, incluida información sobre licitaciones e información perti-

11 Garant, P. Droit administratif. 6. ${ }^{\text {a }}$ ed. Cowansville: Éditions Yvon Blais, 2010, 349 (trad. libre).

12 McCann, J. у Тнівоuтот, M. Régime contractuel de l'État. En JurisClasseur Québec. Droit administratif. Montréal: LexisNexis, 2016, 19/4 (trad. libre). 
nente u oportuna sobre la adjudicación de contratos, a fin de que los licitadores potenciales dispongan de tiempo suficiente para preparar y presentar sus ofertas;

b) La formulación previa de las condiciones de participación, incluidos criterios de selección y adjudicación y reglas de licitación, así como su publicación;

c) La aplicación de criterios objetivos y predeterminados para la adopción de decisiones sobre contratación pública a fin de facilitar la ulterior verificación de la aplicación correcta de las reglas o procedimientos;

d) Un mecanismo eficaz de examen interno, incluido un sistema eficaz de apelación, para garantizar recursos y soluciones legales en el caso de que no se respeten las reglas o los procedimientos establecidos conforme al presente párrafo;

e) Cuando proceda, la adopción de medidas para reglamentar las cuestiones relativas al personal encargado de la contratación pública, en particular declaraciones de interés respecto de determinadas contrataciones públicas, procedimientos de preselección y requisitos de capacitación ${ }^{13}$.

Este convenio ha sido incorporado a los sistemas jurídicos a los cuales se refiere este trabajo, y parecería que aun antes de que la Convención fuese firmada, tanto México como Canadá habían asumido ya en su regulación interna los alcances de dicha convención, de tal forma que esta no hace más que ratificar posiciones existentes.

Ahora bien, tal y como se señaló en líneas precedentes, aun cuando la regulación de los contratos administrativos en México no es reciente, se entiende que en su regulación específica en el derecho público es relativamente nueva. Así, la Constitución Política de los Estados Unidos Mexicanos (CPEUM) preceptúa en los párrafos tercero y cuarto del artículo 134:

Artículo 134.- [...]

Las adquisiciones, arrendamientos y enajenaciones de todo tipo de bienes, prestación de servicios de cualquier naturaleza y la contratación de obra que realicen, se adjudicarán o llevarán a cabo a través de licitaciones públicas mediante convocatoria pública para que libremente se presenten proposiciones solventes en sobre cerrado, que será abierto públicamente, a fin de asegurar al Estado las mejores condiciones disponibles en cuanto a precio, calidad, financiamiento, oportunidad y demás circunstancias pertinentes.

13 Organización de las Naciones Unidas. Resolución 58/4, 31 de octubre de 2003, Convención de las Naciones Unidas contra la Corrupción. 
Cuando las licitaciones a que hace referencia el párrafo anterior no sean idóneas para asegurar dichas condiciones, las leyes establecerán las bases, procedimientos, reglas, requisitos y demás elementos para acreditar la economía, eficacia, eficiencia, imparcialidad y honradez que aseguren las mejores condiciones para el Estado.

La CPEUM es muy clara en cuanto a su regulación; en pocas palabras, todos los contratos del Estado deberán hacerse mediante licitación pública abierta, salvo que no resulte idóneo en términos de la legislación reglamentaria.

En este sentido, como ya se había señalado, la legislación reglamentaria de este precepto constitucional se concreta esencialmente en tres cuerpos normativos (aunque no son los únicos), a saber, la LOPSRM, la LAASSP y la LAPP.

En cuanto a sus contenidos, en términos generales cabe afirmar que por lo menos la LOPSRM y la LAASSP son leyes espejo, es decir que en su contenido resultan prácticamente idénticas (con alguna variación en algún artículo, pero no mucho más que eso).

La primera de las normas regula los contratos de obra pública y demás contratos complementarios y otras figuras complementarias, como sería el caso de la concesión de bienes o servicios. Por su parte, la LAASSP regula las adquisiciones, arrendamientos y contratos de servicios que recibe la Administración Pública de los particulares.

En ambos casos se establece, siguiendo la directriz constitucional, que todos los contratos se adjudicarán a partir de un procedimiento de licitación pública $^{14}$.

La jurisprudencia mexicana ha señalado a propósito de la licitación:

LICITACIÓN PÚBLICA. SU NATURALEZA JURÍDICA.- La licitación pública consiste en un llamado que la administración pública hace a los particulares de forma impersonal para que le formulen ofertas a fin de llevar a cabo una contratación, lo que, de acuerdo con la doctrina, tiene dos consecuencias: a) Quien se presenta y formula una oferta debe ajustarse estrictamente a las condiciones fijadas en el llamado, quedando obligado a mantenerlas durante el plazo que en éste se establezca; y, b) La administración puede aceptar o rechazar las ofertas que se le hagan, sin responsabilidad alguna, siempre y cuando respete la legalidad del procedimiento. Así, aquel llamado implica un conjunto de actos que conforman un procedimiento preparatorio de la actividad contractual del Estado, por lo que la naturaleza jurídica de la licitación pública es la de un procedimiento administrativo integrado por una diversidad de actos administrativos y simples actos de la administración, como formas jurídicas preparatorias de su actividad contractual, de manera que

14 Por licitación pública se entiende el "procedimiento administrativo por el cual la administración pública elige como cocontratante a la persona, física o jurídica, que le ofrece las condiciones más convenientes para el Estado". LóPEz-Elías, J. P. Aspectos jurídicos de la licitación pública en México. México: IIJ-UnAM, 1999, 53. 
su omisión invalida los contratos produciendo su nulidad absoluta o de pleno derecho, la que pueden invocar la propia administración, el particular contratante y los terceros interesados ${ }^{15}$.

En el derecho canadiense, tanto en el ámbito de la Provincia de Quebec como en el nivel nacional se establece que el mecanismo por excelencia para adjudicar un contrato será la licitación pública (l'appel d'offre o call for tender), y al respecto la Corte Superior de la Provincia de Quebec ha señalado de forma muy interesante:

El procedimiento de licitación pública tiene diversos objetivos, entre ellos destacan los siguientes:

1.Permite a la administración pública financiar las obras públicas al mejor precio posible, por medio de la competencia y eliminando las colusiones y esquemas que produzcan patrocinio y otras colusiones.

2. Permite a toda persona competente hacer negocios con el gobierno y los organismos dependientes.

3. Establece un régimen de equidad en el procedimiento de concesión de los contratos, con el objetivo de favorecer la igualdad de oportunidades, reconociendo la importancia de adoptar reglas comunes aplicables por igual a todos los interesados ${ }^{16}$.

De un tenor muy similar es una tesis aislada del Cuarto Tribunal Colegiado en Materia Administrativa del Primer Circuito que señala:

LICITACIÓN PÚBLICA. PRINCIPIOS ESENCIALES QUE RIGEN EL PROCEDIMIENTO ADMINISTRATIVO RESPECTIVO.- El procedimiento administrativo de licitación se rige por los siguientes principios esenciales: 1) Concurrencia, que asegura a la administración pública la participación de un mayor número de ofertas, lo cual permite tener posibilidades más amplias de selección y obtención de mejores condiciones en cuanto a precio, calidad, financiamiento y oportunidad, entre otras; 2) Igualdad, que es la posición que guardan los oferentes frente a la administración, así como la posición de cada uno de ellos frente a los demás; 3) Publicidad, que implica la posibilidad de que los interesados conozcan todo lo relativo a la licitación correspondiente, desde el llamado a formular ofertas hasta sus etapas conclusivas; y, 4) Oposición o contradicción, que deriva del principio de debido proceso que implica la intervención de los interesados en las discusiones de controversia de

15 Tesis Aislada I.4o.A.586 A, emitida por el Cuarto Tribunal Colegiado en Materia Administrativa del Primer Circuito. Novena época. En Semanario Judicial de la Federación y su Gaceta $(\operatorname{SJFy}$ G). T. xxvi, julio de 2007, 2653.

16 Spécialistes en combustion S.D.(1976) lée c. Centre hospitalier Robert-Giffard, 1999 CanLII 11432 (QC CS). 
intereses de dos o más particulares, facultándolos para impugnar las propuestas de los demás y, a su vez, para defender la propia ${ }^{17}$.

Resulta por demás interesante el hecho de que surgen dos criterios en el mismo sentido y prácticamente por las mismas razones en relación con los principios y valores detrás de la licitación pública, pese a surgir de dos sistemas jurídicos completamente distintos, esto es, el canadiense y el mexicano. Este punto se retoma más adelante.

En el caso del derecho mexicano, ambos cuerpos normativos establecen que se acudirá en primer término a la licitación abierta nacional (salvo que un tratado internacional establezca lo contrario), y en su defecto, cuando la licitación abierta no sea efectiva, se acudirá a la invitación a por lo menos tres personas o licitación cerrada (aunque esta denominación no es utilizada por el legislador).

También es de destacar, en este punto que, en relación con la asociación público-privada, la LAPP no hace mención de que para la adjudicación del contrato se utilizará la licitación pública, sino que se refiere a un procedimiento de concurso $^{18}$. Aunque en un sentido práctico en cuanto a la redacción de la norma no es posible afirmar que realmente esto implique alguna diferencia real con la licitación pública, no se debe perder de vista que tanto la licitación como el concurso son procedimientos al alcance del Estado para seleccionar, en el caso de la primera, las mejores condiciones para el Estado, en contraposición al concurso, cuyo objetivo es buscar a la persona idónea. El concurso, en términos generales, es uno de los mecanismos propios para elegir a los funcionarios públicos, no para la celebración de un contrato administrativo; sin embargo, tratando de entender la naturaleza de la asociación público-privada, cabe interpretar que la intención del legislador al señalar que se refiere a concurso como procedimiento adjudicatorio es que se trata de buscar al socio idóneo para el Estado, no de encontrar las mejores condiciones para el Estado.

Para algunos podría ser esto un motivo de impugnación en la vía de amparo, toda vez que al no referirse la LAPP expresamente a licitación pública, se podría entender que está violando el texto del artículo 134 constitucional. Acá se considera que este no sería un argumento suficiente para la impugnación y al parecer, hasta hoy, no hay ningún pronunciamiento judicial al respecto.

Ahora bien, del propio texto constitucional se desprende que si la licitación no resultase el medio idóneo para la adjudicación de un contrato, la

17 Tesis I.4o.A.587 A, Cuarto Tribunal Colegiado en Materia Administrativa del Primer Circuito. Novena época. En Semanario Judicial de la Federación y su Gaceta (SJFyG). T. xxvi, julio de 2007, 2652 .

18 Cfr. art. 38 LAPP. Por concurso, en palabras de Héctor Escola, se entiende "el procedimiento de oposición que se lleva a cabo para elegir el cocontratante de la Administración Pública atendiendo principalmente a la capacidad científica, técnica, cultural o artística de las personas que se presentan a él, a fin de seleccionar a aquellas que tengan la mayor capacidad”. Citado

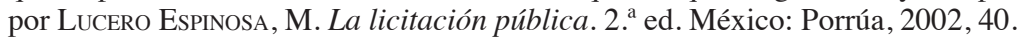


legislación reglamentaria establecerá los mecanismos y las oportunidades en que no se agotará la licitación y por tanto se acudirá a la adjudicación directa. Estas razones, reguladas por los artículos 41 de la LAASSP y 42 de la LOPSRM, se pueden sintetizar como sigue:

- Cuando se trate de bienes o servicios sobre los que no exista ninguna alternativa, o bien, se trate de una titularidad o licenciamiento de una patente o derechos de autor, o por tratarse de obras de arte.

- Cuando se ponga en peligro o se altere el orden social, la economía, los servicios públicos, salud pública, la seguridad o el ambiente de alguna zona o región del país como consecuencia de un caso fortuito o fuerza mayor.

- Cuando se esté ante pérdidas o costos adicionales importantes, cuantificados y justificables.

- Cuando se esté ante contratos que tengan fines exclusivamente militares o se ponga en riesgo la seguridad nacional o la seguridad pública.

- Cuando existan razones de urgencia para la obtención de los bienes, servicios o la ejecución de la obra.

- Cuando se haya rescindido un contrato adjudicado por licitación pública.

- Cuando se trate de bienes perecederos, granos y productos alimenticios básicos o semiprocesados.

- Cuando se trate de servicios de consultorías, asesorías, estudios o investigaciones.

- Cuando se trate de bienes, servicios o ejecución de trabajos como dación en pago.

- Cuando se trate de bienes o servicios relativos a la operación de instalaciones nucleares.

- Cuando se trate de contratos derivados de un contrato marco ${ }^{19}$.

- Cuando se trate de trabajos que requieran fundamentalmente mano de obra campesina o urbana marginada.

En el derecho canadiense, específicamente en la Provincia de Quebec, se alude a la adjudicación directa como un contrato gré à gré (mutual agreement contract) -denominación también adoptada en el ámbito federal-, y este aparece como excepción al procedimiento de licitación.

En cuanto a la regulación en el ámbito local, el artículo 13 de la LCOP establece que la excepción a la licitación se configura:

19 El contrato marco es un acuerdo de voluntades que celebra un órgano público con uno o más posibles proveedores, mediante el cual se establecen de manera general las especificaciones técnicas y de calidad, alcances, precios y condiciones que regularán la adquisición o arrendamiento de bienes o la prestación de servicios que, posteriormente, mediante contratos específicos, en su caso, formalizarán otros órganos administrativos. Cfr. párr. 2. ${ }^{\circ}$ del art. 17 LAASSP. 
1. ${ }^{\circ}$ si existe una situación de urgencia, que importe peligro para las personas o para la propiedad;

$2 .^{\circ}$ si solo existe un contratista posible, en virtud de la existencia de una garantía, un derecho de propiedad o un derecho exclusivo, como sería el caso de los derechos de propiedad intelectual o un derecho basado en la exclusividad de una licencia o patente, o por su valor artístico, patrimonial o museológico de la propiedad requerida o servicio;

3. ${ }^{\circ}$ si el contrato involucra información confidencial o protegida, cuya apertura en una licitación ponga en riesgo su confidencialidad o bien, lesione al interés público;

4. ${ }^{\circ}$ si el organismo público considera que puede acreditar [...] que la licitación pública no serviría para tutelar al interés público dado el objeto del contrato; o,

$5 .^{\circ}$ En cualquier otro caso determinado por la regulación gubernamental ${ }^{20}$.

De otra parte, en el caso de la regulación federal se destacan: a) los casos de urgencia, b) los límites en cuanto a montos, es decir, que se trate de cantidades relativamente pequeñas, c) los casos en los que la licitación no sea el mecanismo adecuado para la tutela del interés público y, d) los casos en los que el contrato solo pueda ser ejecutado por una sola persona ${ }^{21}$.

Es importante señalar que en el derecho de Canadá, el contrato de asociación público-privada (partenariat public-privé) está regulado también por la LCOP, y por tanto también está sometido a las reglas de la licitación pública.

En conclusión, se puede señalar que, aun cuando la regulación canadiense contempla supuestos mucho más abiertos que los del derecho mexicano, la realidad es que, grosso modo, no hay una diferencia real entre las excepciones a la licitación contempladas por ambos países.

\section{LOS TIPOS DE CONTRATOS ADMINISTRATIVOS}

Los diversos tipos de contratos administrativos que se contemplan en el derecho mexicano son los siguientes: a) obra pública ${ }^{22}$, b) adquisiciones ${ }^{23}$,

20 Art. 13 LCOP.

21 Cfr. art. 6 RME.

22 Regulado por la LOPSRM, y que en palabras de Parada se entiende como "el celebrado entre la Administración y un empresario, cuyo objeto sea la construcción de bienes que tengan naturaleza inmueble, la realización de trabajos que modifiquen la forma o la sustancia del terreno o del subsuelo, la reforma, reparación, conservación o demolición de los objetos anteriores". PARAdA, R. Derecho Administrativo I. Parte general. 13. ${ }^{\text {a }}$ ed. Madrid: Marcial Pons, 2002, 339.

23 Regulado por la LAASSP. 
c) arrendamientos ${ }^{24}$, d) servicios ${ }^{25}$ y e) asociación público-privada ${ }^{26}$, recordando que en líneas precedentes se señaló el contrato marco, tipo de contrato que es más bien un contrato de adhesión previo a las adquisiciones.

De nuevo, la doble influencia que existe en el derecho canadiense (especialmente en el derecho de Quebec) se hace presente en el tema de los contratos administrativos, con una fuerte influencia del derecho francés (al igual en el derecho mexicano), respecto del cual se ha señalado:

Los contratos de la Administración son [...] muy numerosos y de una gran diversidad. Y dentro de esa masa desordenada se pueden distinguir dos grandes categorías que están enmarcadas de manera precisa dentro de la ley, siendo los contratos públicos [marchés publics] y las delegaciones del servicio público formas de contratos bastante antiguas ${ }^{27}$.

24 Ibíd.

25 Ibíd. En términos de lo dispuesto por el artículo 3 de la LAASSP, los contratos regulados por ella son:

"I. Las adquisiciones y los arrendamientos de bienes muebles;

"II. Las adquisiciones de bienes muebles que deban incorporarse, adherirse o destinarse a un inmueble, que sean necesarios para la realización de las obras públicas por administración directa, o los que suministren las dependencias y entidades de acuerdo con lo pactado en los contratos de obras públicas;

"III. Las adquisiciones de bienes muebles que incluyan la instalación, por parte del proveedor, en inmuebles que se encuentren bajo la responsabilidad de las dependencias y entidades, cuando su precio sea superior al de su instalación;

"IV. La contratación de los servicios relativos a bienes muebles que se encuentren incorporados o adheridos a inmuebles, cuyo mantenimiento no implique modificación alguna al propio inmueble, y sea prestado por persona cuya actividad comercial corresponda al servicio requerido;

"v. La reconstrucción y mantenimiento de bienes muebles; maquila; seguros; transportación de bienes muebles o personas, y contratación de servicios de limpieza y vigilancia;

"vI. La prestación de servicios de largo plazo que involucren recursos de varios ejercicios fiscales, a cargo de un inversionista proveedor, el cual se obliga a proporcionarlos con los activos que provea por sí o a través de un tercero, de conformidad con un proyecto para la prestación de dichos servicios;

"VII. La prestación de servicios de personas físicas, excepto la contratación de servicios personales subordinados o bajo el régimen de honorarios;

"VIII. La contratación de consultorías, asesorías, estudios e investigaciones, y

"IX. En general, los servicios de cualquier naturaleza cuya prestación genere una obligación de pago para las dependencias y entidades, salvo que la contratación se encuentre regulada en forma específica por otras disposiciones legales. Corresponderá a la Secretaría de la Función Pública, a solicitud de la dependencia o entidad de que se trate, determinar si un servicio se ubica en la hipótesis de esta fracción".

26 Regulada por la LAPP, y que en términos de su artículo 2 son: "aquellos que se realicen con cualquier esquema para establecer una relación contractual de largo plazo, entre instancias del sector público y del sector privado, para la prestación de servicios del sector público o al usuario final y en los que se utilice infraestructura provista total o parcialmente por el sector privado con objetivos que aumenten el bienestar social y los niveles de inversión en el País".

27 Morand-Deviller, J. Droit administratif. 12. a ed.. Paris: Montchrestien Lextenso, 2011, 394 (trad. libre). 
Siguiendo esta influencia, el texto de la LCOP establece como contratos administrativos:

(1) los contratos de suministro o adquisiciones, incluyendo los contratos para la compra o renta de bienes muebles, dentro de los cuales pueden incluirse los costos de instalación, funcionamiento y mantenimiento de dichos bienes;

(2) los contratos de obra pública, regulados por la Ley de Construcciones (Loi sur le bâtiment), por lo que el contratista debe ser titular de una licencia en los términos del capítulo iv de dicha ley;

(3) los contratos de servicios, distintos de los contratos para integrar obras de arte a la arquitectura y al ambiente de los edificios y espacios públicos.

Igualmente se consideran contratos sujetos a esta ley, con independencia de que recurran a fondos públicos o no:

(1) los contratos de asociación público-privada, cuyo objeto sea el desarrollo de un proyecto de infraestructura, en los que el organismo público se asocia con un contratista para el diseño, ejecución y explotación de dicha infraestructura;

(2) cualquier otro contracto que así se determine por reglamento de gobierno.

En el ámbito federal, el RME establece que serán considerados contratos administrativos: a) la adquisición de bienes (artículos, productos, instrumentos, mercancías, materiales o suministros), b) la contratación de servicios (excepto la contratación de personal calificado al servicio de su Majestad) y c) los contratos de obra pública, en los que se incluyen los trabajos de construcción, reparación, renovación o restauración de una obra, exceptuando las navieras (se incluyen la instalación de estructuras prefabricadas, obras de dragado, demoliciones y la renta de equipo directamente vinculada a la ejecución del (contrato) $)^{28}$.

\section{REGLAS DE FORMACIÓN DE LOS CONTRATOS}

Se parte de la idea de competencia, que en palabras del mexicano Acosta Romero es "la facultad para realizar determinados actos, que les atribuye a los órganos de la Administración Pública el orden jurídico"29; por tanto, la competencia es un presupuesto de la autoridad administrativa para la celebra-

28 Cfr. art. 2 RME.

29 Acosta Romero, M. Compendio de derecho administrativo. Parte general. México: Porrúa, 1996, 375. 
ción de un contrato administrativo. Equivale, pues, a la capacidad jurídica, tratándose de las personas de derecho privado.

Lo anterior resulta perfectamente válido para el derecho administrativo mexicano, siendo suficiente que exista una norma jurídico-administrativa habilitante para que el funcionario tenga la competencia necesaria para la celebración del contrato administrativo.

Sin embargo, en el ámbito del derecho canadiense, esto no necesariamente opera de la misma manera, pues aunque también se parte de la idea de que el funcionario debe ser competente para la celebración del contrato, el origen de la competencia puede tener algunas implicaciones peculiares. Las reglas relativas a la competencia en materia de contratos administrativos ${ }^{30}$ en Canadá, se pueden enunciar de la siguiente forma.

Primera regla. Una administración pública solamente puede contratar cuando se trate del cumplimiento del objeto de sus atribuciones en razón de la materia (ratione materiae). Los mexicanos Delgadillo Gutiérrez y Lucero Espinosa señalan que "[e]l órgano administrativo debe ser competente para la celebración del contrato, toda vez que si no lo fuera existiría un vicio que lo tornaría nulo. $\mathrm{Al}$ actuar de acuerdo con su competencia y en ejercicio de la función administrativa deberá sujetarse a las disposiciones legales respecto de sus facultades" ${ }^{31}$.

Una distinción importante en este punto, tal como lo recuerda Garant, y originalmente planteada por Stanley De Smith, es que la Corona, como corporación del common law, tiene una competencia ilimitada en potencia para contratar, excepto si está expresamente impedida para ello en términos de una ley (statute) o un principio del common law que se superponga a esa competencia. Las entidades públicas solo pueden celebrar contratos públicos dentro del espectro de su autoridad ${ }^{32}$. Posición que ha sido reiterada por la Suprema Corte canadiense ${ }^{33}$.

Segunda regla. En ausencia de una legislación restrictiva, o ante la inexistencia de disposición legal en contrario, un órgano de la Administración gubernamental puede celebrar contratos sin tener autorización expresa mediante ley o resolución del Consejo, esto en virtud de la doctrina del mandato aparente o de la delegación de poder. De acuerdo con esta doctrina, el funcionario público puede celebrar un contrato, a nombre y título del gobierno, aun sin tener disposición expresa que lo faculte, dentro del marco general de sus atribuciones ${ }^{34}$.

30 Cfr. Garant. Droit administratif, cit., 363 ss.

31 Delgadillo Gutiérrez, L. H. y Lucero Espinosa, M. Compendio de derecho administrativo. Primer curso. 3. a ed. México: Porrúa, 1998, 318.

32 Cfr. Garant. Droit administratif, cit., 363.

33 Cfr. P. G. Québec v. Labrecque \& al. (1980) 2 RCs 1057.

34 El artículo 2136 CCQ señala que el mandato no está restringido a un acto exclusivo, sino que incluye todos aquellos propios del cumplimiento del objeto del mandato. Adicionalmente, 
De otra parte, en el marco de la delegación implícita del poder ha cobrado especial importancia el fallo en el caso Carltona Ltd.v. Commisions of Works de la jurisprudencia inglesa, del que se desprende lo siguiente:

En la administración del gobierno en este país, las funciones que les son otorgadas a los Ministros (propiamente otorgadas por la Constitución, al ser los ministros los responsables de ellas por mandato constitucional) son tan diversas que ningún ministro podría atender personalmente a todas [...] No se puede suponer que esta regulación significa que, en cada caso, el ministro en persona debe estar abocado al asunto en concreto. Los deberes impuestos a los ministros y los poderes que se les otorgan son normalmente ejercidos por otros agentes oficiales pertenecientes al mismo departamento, bajo la autoridad de los ministros. De no ser así, los negocios públicos no podrían ser ejecutados. Constitucionalmente, la decisión sobre ese agente oficial es, por supuesto, la decisión del ministro. El ministro es responsable. Es él quien responde ante el Parlamento por cualquiera de las cosas que sus oficiales hayan realizado bajo su autoridad [...] Todo el sistema de organización y administración departamental está basado en que los ministros, siendo responsables ante el Parlamento, deberán velar por que las labores importantes sean encargadas a oficiales experimentados ${ }^{35}$.

Es importante señalar que para el contratista del Estado deberá existir también una total transparencia en cuanto a las atribuciones de las que goza el funcionario u oficial con el que se realizará el negocio contractual, de tal forma que el contratista, si es que las atribuciones del funcionario están claramente definidas en cuanto a su competencia y sus limitaciones, no podrá hacer valer a su favor la teoría de la competencia aparente del funcionario, pues no sería el caso ${ }^{36}$.

De cualquier forma, el tema relativo al mandato aparente y a la delegación implícita de poderes hoy en día no está exento de debate, de tal forma que en la gran mayoría de los casos dependerá de la resolución judicial que recaiga sobre el contrato si es que este es impugnado ${ }^{37}$.

Tercera regla. Un órgano administrativo no puede obligar contractualmente a la Administración infragubernamental sin contar con una disposición habilitante expresa en la ley, en un reglamento o en una resolución válidamente adoptada.

Esta regla está referida a los órganos y organismos estatutariamente constituidos y, como señala Garant, "la verdadera razón de esta diferencia es que

así ha sido sostenido por la jurisprudencia canadiense. Cfr. The Queen v. Transworld Shipping Ltd., 1975 CanLII 1051 (FCA).

35 [1943] 2 All E. R. 560 (trad. libre).

36 Woodburn c. La Reine (1898) 29 SCR 112.

37 Cfr. Моцот, H. L. The Carltona Doctrine and the Recent Amendments to the Interpretation Act. En Ottawa Law Review. Vol 26, n. ${ }^{\circ}$ 2, 1994, 257-283. 
los poderes de los organismos públicos estatutarios, contrariamente a los de la Corona, son interpretados de forma estricta" ${ }^{38}$. A diferencia de la anterior regla, referida a los ministerios y a la Corona, los organismos estatutarios, es decir, aquellos creados expresamente por la ley, se encuentran fuertemente sometidos al principio de legalidad, y por tanto la interpretación jurisprudencial sobre sus atribuciones ha sido igualmente interpretada con rigor. En los sistemas de civil law, claramente esto no causa ninguna extrañeza pues simplemente nos estamos refiriendo al entendimiento clásico de competencia. En palabras de los españoles Gamero Casado y Fernández Ramos, "el órgano que debe dictar el acto se encuentra establecido en las normas atributivas de las competencias administrativas [...] requiere de una norma atributiva concreta y sólo podrá alterarse el ejercicio de la competencia por los mecanismos ya conocidos: delegación, avocación, sustitución, etc..”39.

Aunque también se reconoce por la Corte que en casos de urgencia se puede justificar cierta flexibilidad en cuanto a esta regla. De la misma forma, las compras ordinarias o, mejor dicho, cotidianas, no se consideran contratos en sentido estricto, sino más bien operaciones del día a día que han de realizar los funcionarios o agentes públicos.

Cuarta regla. A menos que esté expresamente autorizado por una ley, la Administración no puede modificar mediante contrato una ley, violar una ley o un reglamento de orden público.

Aunque esta regla resulta un poco extraña a la luz de las concepciones propias del civil law, hace referencia a que las atribuciones de la autoridad administrativa no son renunciables mediante contrato administrativo, en aquellos supuestos en los que se trate de disposiciones que afecten al orden público, estén en contravención de una ley y, por supuesto, cuando atenten contra derechos fundamentales. En caso contrario, el contrato es nulo. Sin embargo, es posible entender que, tratándose de disposiciones que no afecten al orden público, cuando no se trate de una actuación expresamente contra lege o bien que importe peligro de una afectación a derechos fundamentales, la Administración contratante puede acordar ciertas omisiones o, mejor dicho, abstenerse de ciertas acciones (en relación con el contrato mismo) de común acuerdo con el contratista.

No se debe perder de vista que en la visión canadiense del contrato administrativo este se entiende como ley entre las partes, de acuerdo con el Código Civil, en el caso de Quebec, y por tanto se trata esencialmente de un acto administrativo subordinado a la ley y a otros reglamentos ${ }^{40}$.

38 Garant. Droit administratif, cit.

39 Gamero CASAdo, E. y Fernández Díaz, S. Manual básico de derecho administrativo. Madrid: Tecnos, 2008, 377.

40 Cfr. Garant. Droit administratif, cit., 374-375. 
Quinta regla. La autoridad contratante no puede, mediante contrato, comprometerse a limitar o renunciar a sus poderes, privilegios e inmunidades que fueron conferidos por la ley o una prerrogativa, o limitar indebidamente el ejercicio de los mismos.

En virtud de un elemental principio de soberanía del Parlamento es que la Administración no puede renunciar o modificar sus prerrogativas vía contrato (o cualquier otra vía), sino que esto le corresponde únicamente al propio Parlamento (en términos de la Ley de Interpretación, art. 42 (1)), mediante la modificación de sus propias normas. Al respecto, la jurisprudencia ha sido firme $^{41}$. Es importante señalar que esta regla, en términos generales, hace referencia a disposiciones de leyes fiscales; por ejemplo, aquella según la cual la administración municipal no puede establecer el pago de impuestos en contravención a la exención reconocida por el artículo 125 de la Constitución.

Sexta regla. La autoridad pública contratante no puede celebrar ningún contrato que tenga por efecto limitar la libertad de acción que requiere para el ejercicio de sus poderes en el interés público.

Esta regla encuentra su raíz en la llamada freedom of executive action, que tiene su origen en el fallo británico en el caso Rederiaktiebolaget Amphitrite v. The King. A este respecto señala Nolen:

El principio de common law de la necesidad ejecutiva le otorga al gobierno la capacidad para concluir un contrato (de otra forma vinculante), si es que existe un impedimento para ejercer una acción ejecutiva o legislativa, sin pagar compensación alguna a la otra parte contratante. El razonamiento que explica este principio es que sería inapropiado que un gobierno elegido decidiera que no puede hacer algo que el interés público requiere, por ejemplo, construir un camino o una escuela, como consecuencia de una limitación impuesta por un contrato privado ${ }^{42}$.

Es importante señalar que esta regla no se refiere a la facultad que tiene la Administración Pública para rescindir el contrato únicamente por razones de oportunidad (como sí ocurre en el contexto latinoamericano). Por el contrario, el principio de libertad de acción ejecutiva se encamina a la irrenunciabilidad por parte de la Administración de sus propias atribuciones. Tal y como lo ha asumido la jurisprudencia canadiense, " $[u] n$ ministro no puede, mediante acuerdo, privarse a sí mismo de un poder que le corresponde ejercer cuando así sea requerido en virtud del interés público, ni puede, válidamente, convenir abstenerse de usar ese poder cuando así se requiera" ${ }^{43}$. Si la Administración

41 Cfr. Renvoi sur le Régime d'assistance publicque du Canada, [1991] 2RCs 525.

42 Nolen, S. Managing government contracts and Remedies for Breach. Disponible en: www.vgso.vic.gov.au/sites/default/files/Managing\%20Government\%20Contracts\%20July\%20 2010.pdf (Consultado el 6 de febrero de 2017) (trad. libre).

43 Cfr. The King v. Dominion of Canada Pstage Stamp Vending [1930] RCS 500. 
actuase en contrario, claramente atentaría contra el interés público, y por tanto en violación de las políticas públicas y de la justicia natural.

Séptima regla. La Administración Pública puede contratar de forma oral, salvo que la ley le exija que lo haga por escrito.

Probablemente, bajo las reglas de la tradición romano-canónica, esta sea de una de las reglas que más llamen la atención, pues en esta tradición parecería una obviedad el requisito de que el contrato se establezca por escrito.

Ahora bien, también debemos destacar que la legislación en Canadá, en términos generales, establece que los contratos que celebren las autoridades administrativas deberán hacerse por escrito, y que dado que los contratos administrativos tienen una inspiración y base en el derecho civil, donde se contemplan sin duda los llamados contratos consensuales o no formales (contrato oral), también es cierto que esta posibilidad de que la Administración celebre un contrato oral es realmente limitada. Se debe tomar en consideración que tiene que existir algún registro documental de la aceptación del contrato, así como de las condiciones generales bajo las cuales dicho contrato se ejecutará. En todo caso, la jurisprudencia canadiense ha insistido en la necesidad de establecer que exista algún tipo de manifestación del consentimiento por escrito, para que se interprete que existe un contrato ${ }^{44}$.

\section{REGLAS PARA LA EJECUCIÓN DE LOS CONTRATOS}

En cuanto a la ejecución de los contratos, son muchos los temas que se pueden abordar y, sin duda, a todos y cada uno de ellos se les podrían dedicar muchas páginas para analizar sus alcances. Sin embargo, para efectos de este trabajo, lo que se procura hacer es un ejercicio de confrontación de las distintas reglas que existen en los dos regímenes señalados.

\subsection{Fiscalización de contratos administrativos}

En primer término, sin duda alguna, la fiscalización de estos contratos corresponde a uno de los temas de mayor calado en la doctrina y la práctica durante los últimos años; por ello, se deben considerar las reglas relativas a la fiscalización de los contratos administrativos.

Tratándose de las adquisiciones, arrendamientos y servicios, la LAASSP establece en el artículo 58 que la autoridad podrá verificar la calidad de los bienes o servicios objeto del contrato. En contraposición, en términos del artículo 53 de la LOPSM, la autoridad designará a un funcionario público, "quien fungirá como su representante ante el contratista y será el responsable directo 
de la supervisión, vigilancia, control y revisión de los trabajos, incluyendo la aprobación de las estimaciones presentadas por los contratistas" 45 .

Tratándose de las APP, la LAPP señala que la función de supervisión la ejercerá la Secretaría de la Función Pública, la cual será responsable de verificar el cumplimiento de la asociación y, dado el caso, imponer las sanciones correspondientes ${ }^{46}$. Asimismo, la dependencia contratante podrá designar a un interventor cuando se ponga en peligro la ejecución de la APP y tendrá derecho a los rendimientos correspondientes si es que estos se generan, en tanto el asociado regulariza su situación ${ }^{47}$.

En el derecho canadiense, en concreto en la legislación de Quebec, se establece que el titular de la dependencia pública tendrá la obligación de nombrar a un oficial que dé cumplimiento a las reglas contractuales ${ }^{48}$. Asimismo, la función de verificación y fiscalización de la ejecución de los contratos recaerá en el Conseil du trésor ${ }^{49}$, que en muchos sentidos funciona como un ministerio de administraciones públicas.

En el contexto de la contratación administrativa canadiense, aun cuando se parte de la base de que no existe ninguna diferencia esencial entre un contrato de derecho privado y uno de derecho público, se asume que, en virtud de interés público que es preciso tutelar tratándose de los segundos, el contratista tiene la obligación de soportar todo tipo de verificaciones y fiscalizaciones en cuanto al cumplimiento del objeto del contrato, dentro de un margen de razonabilidad y justicia natural. Los criterios bajo los cuales se verificará el cumplimiento serán los determinados en los diversos Cahiers des charges et devis généraux ${ }^{50}$, los cuales funcionan como normas técnicas de vinculación jurídica indirecta, es decir, se trata de normas de derecho suave ${ }^{51}$.

Resulta obvio que de la facultad de fiscalización con que cuenta la Administración Pública tratándose de los contratos administrativos, se desprende la facultad de sanción, y que en el derecho francés puede consistir en: a) una sanción pecuniaria, b) la interrupción del contrato por culpa del contratista y c) la rescisión del contrato ${ }^{52}$.

45 Art. 53 LOPSRM.

46 Cfr. art. 125 LAPP.

47 Cfr. art. 112 LAPP.

48 Cfr. arts. 21.0.1 y 21.0.2 LCOP.

49 Cfr. art. 21.1 LCOP.

50 A falta de una mejor traducción, Cuadernos de Cargas y Especificaciones Generales, que expide cada dependencia según corresponda a su actividad. Cfr., p. ej.: http://collections. banq.qc.ca/ark:/52327/bs2748781, que contiene el Cahier des charges et devis générauxInfrastructures routières - Services de nature techniques [en línea], Gobierno de Quebec, 2017 (consultado el 28 de febrero de 2017).

51 En el caso del derecho mexicano, esto perfectamente podría ser equiparado a las Normas Oficiales Mexicanas y circulares administrativas que rigen en materia de contratos públicos.

52 Cfr. Morand-Deviller. Droit administratif, cit., 406. 


\subsection{Modificación de contratos administrativos}

En términos generales, es posible afirmar que existen cuatro formas de modificación de los contratos administrativos: a) por mutuo consentimiento, b) por situaciones sobrevinientes, c) por intervención directa de legislador y d) por modificación unilateral del contrato por parte de la Administración.

La primera de las formas se refiere al mutuo consentimiento, es decir, al acuerdo de las partes, pudiéndose decir que forma parte de la naturaleza de los contratos. No obstante, no se debe perder de vista que mientras que los contratos de derecho privado se rigen por la autonomía de la voluntad y, por tanto, el contrato como tal se convierte en lex inter partes, los contratos administrativos propios de los sistemas que siguen al derecho francés no se pueden entender en esos términos, sino que la voluntad, por lo menos de la Administración, está sometida de manera absoluta a la ley.

En el derecho mexicano, la legislación en materia de contratos administrativos admite la celebración de convenios modificatorios, principalmente cuando sea necesario realizar ajustes de precios o incluso en cuanto a las condiciones de plazos y entregas, siempre y cuando no sea por causas imputables a ninguna de las partes. En todo caso, estos convenios "no podrán, en modo alguno, afectar las condiciones que se refieran a la naturaleza y características esenciales del objeto del contrato original, ni convenirse para eludir en cualquier forma el cumplimiento de esta Ley o de los tratados" 53 . Es decir, está legislada la posibilidad de modificar los contratos administrativos por mutuo consentimiento, siempre y cuando se trate de modificaciones necesarias para el debido cumplimiento del objeto del contrato.

En contraposición, en el derecho canadiense, toda vez que el contrato administrativo, se insiste, se rige por el derecho común, se entiende que el principio de la inmutabilidad de las obligaciones contractuales también será aplicado a este ${ }^{54}$. Así, en esta línea de pensamiento, se parte de la base de que el contrato admite modificaciones, pero estas tienen que ser planteadas de forma cuidadosa, máxime dado que la legislación aplicable es bastante restrictiva en este sentido. No obstante, la Corte Suprema canadiense ha hecho una interpretación un poco más flexible al respecto, distinguiendo incluso entre modificaciones sustanciales y modificaciones accesorias, debiendo en todo caso analizarse el caso concreto ${ }^{55}$ para determinar si la modificación resulta contraria a derecho o no, por lo que hace a las cuestiones sustanciales; pero, tratándose de las accesorias, incluso ha incorporado reglas de aceptación tácita, de tal forma que es posible encontrar modificaciones, sin necesidad

53 Art. 59, párr. $4 .^{\circ}$ LOPSRM.

54 Cfr. Garant. Droit administratif, cit., 427-428.

55 Cfr. Adricon v. East Angus [1978] 1 RCs 1107. 
de que estas sean convenidas, aun cuando sí tiene que existir algún tipo de expresión por escrito (p. ej., respecto del pago en un ajuste de precios).

El segundo supuesto, relativo a la fuerza mayor o causa sobreviniente no imputable a ninguna de las partes, tanto en el derecho mexicano como en el canadiense se contempla la posibilidad de suspender la ejecución del contrato, y en todo caso se cubrirán los montos correspondientes a los trabajos ya realizados, los bienes efectivamente entregados o los servicios ya prestados ${ }^{56}$.

Ahora bien, en cuanto a la modificación del contrato por intervención del legislador, se debe partir de que es poco probable que el legislador realice algún tipo de modificación a la ley que llegue a impactar directamente la ejecución de un contrato ${ }^{57}$; sin embargo, es razonable estar abiertos a esta posibilidad, así que dependiendo de la situación concreta que se presente, el contratista podría llegar a recurrir a la indemnización en determinado momento, o la Administración podría verse en la necesidad de hacer alguna modificación en relación con la ejecución del contrato. Esta posición resulta más que válida para ambos sistemas jurídicos.

Sin embargo, no está de más tener presente el señalamiento del mexicano López Olvera, en el sentido de que "[n]o es en los actos individuales donde la administración despliega toda su arbitrariedad: es en la redacción de largos y pesados reglamentos, seudo normas generales que luego maliciosamente alega limitarse a cumplir, cuando ella misma los ha preparado y emitido" 58 .

Se insiste, resulta poco probable que la Administración Pública modifique su normatividad con el fin de eludir una responsabilidad contractual y, en todo caso, en un sistema como el mexicano, cualquier modificación normativa apareja en sus disposiciones transitorias prevenciones relativas a situaciones que se pudiesen presentar en virtud de los contratos que se estén ejecutando.

En contraposición, en el derecho canadiense, autores como Garant estiman que, bajo ciertas condiciones, el reglamento sí podría modificar un contrato, pero para que la Administración pueda modificar ese reglamento deberá contar con autorización legislativa para ello, y, por supuesto, podría incurrir en algún tipo de responsabilidad ${ }^{59}$.

Por último, prácticamente toda la doctrina iberoamericana contempla la posibilidad de la modificación unilateral del contrato administrativo, lo que tiene origen principalmente en el derecho francés. En palabras de Lombard y Dumont:

56 Cfr. arts. 55 bis LAASSP, 45 bis LOPSRM y 1470 CCQ.

57 Se suelen incluir disposiciones transitorias para salvar la ejecución de las obras, la prestación de los servicios o las adquisiciones derivadas.

58 López Olvera, M. A. La instancia administrativa. Problemas actuales de la justicia administrativa. Principios y fuentes del proceso administrativo. Órgano y procedimientos judiciales. Buenos Aires: Ediar, 2008, 81.

59 Cfr. Lévis (Ville) c. Services sanitaires Champlain ltée, 1987 CanLII 501 (QC CA). Disponible en: http://canlii.ca/t/1ppm2 (Consultado el 8 de febrero de 2017). 
El poder de modificación unilateral de los contratos está reconocido desde hace mucho tiempo por la jurisprudencia. El Consejo de Estado ha admitido, desde 1910, que un prefecto podría modificar el servicio de una compañía de trenes, ya establecido en el contrato (CE 21 de marzo de 1910, Compagnié générale française des tramways, GAJA n..$^{\circ} 21$ ), ya que cuenta con el poder suficiente y necesario para determinar dichas modificaciones y adiciones con el fin de asegurarse de que, protegiendo al interés público, el servicio funcionará de forma normal ${ }^{60}$.

Sin embargo, el ordenamiento mexicano no está adherido a esta posición, pues las modificaciones que se pueden hacer sobre el contrato administrativo, deberán hacerse dentro de los límites que señalados por la legislación y mediante la celebración de un convenio modificatorio, teniendo como límite, tal como se indicó en líneas precedentes, que no se modifique el objeto y alcances del contrato; y aun ante cuestiones imprevisibles, a menos que el objeto del contrato desaparezca, la modificación del contrato no puede hacerse de forma unilateral.

Por su parte, el derecho canadiense, como se indicó, parte del principio de la inmutabilidad de la obligación, por lo que cabría aventurarse a señalar, siguiendo a Garant ${ }^{61}$, que la teoría de la imprevisión no está contemplada por su sistema jurídico (por lo menos en el ámbito de Quebec). De hecho, la Corte de Apelaciones de Quebec así lo ha señalado ${ }^{62}$.

\subsection{Rescisión del contrato administrativo}

Se entiende la rescisión como la "privación de efectos de un negocio jurídico por sí mismo válido para lo futuro, por medio de una declaración de voluntad"63. Siguiendo a la profesora emérita de la Universidad de París I (Panthéon-Sorbonne), Jacqueline Morand-Deviller, la rescisión puede presentarse de tres formas: a) rescisión como sanción, b) rescisión por causa del interés general y c) rescisión por inejecución no infractora ${ }^{64}$.

En el derecho mexicano se contempla la rescisión administrativa como una forma de sanción, siempre y cuando se agote el procedimiento sancionador respectivo ${ }^{65}$. Siguiendo el mismo orden de ideas, la rescisión por causa de interés general está regulada en México tanto en la LAASsP ${ }^{66}$ como en la

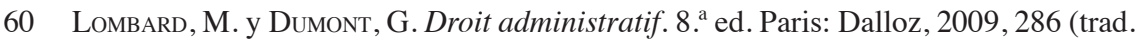
libre).

61 Cfr. Garant. Droit administratif, cit., 434-435.

62 Cf. Walsh \& Brais Inc. c. Montréal (Communauté urbaine), 2001 CanLII 20665 (QC CA). Disponible en: http://canlii.ca/t/1fcm7 (Consultado el 8 de febero de 2017).

63 AA.vv. Enciclopedia Jurídica Mexicana. T. vi, México: IIJ-unam/Porrúa, 2002.

64 Cfr. Morand-Deviller. Droit administratif, cit., 407-409.

65 Cfr. arts. 61 LOPSRM; 54 LAASSP y, 122 LAPP.

66 Cfr. art. 54 BIS LAASSP. 
LOPSRM $^{67}$, pero no así para las APP. Por último, la rescisión por inejecución no infractora, no está regulada como tal en el derecho mexicano y se entiende más bien como una terminación anticipada del contrato, tomando en consideración que le resultaría imposible al contratista cumplir con el objeto del contrato. En estos casos, dependiendo de la etapa de ejecución en la que se encuentre el contrato, será la consecuencia inmediata; sin embargo, no está de más señalar que en todo caso la fianza otorgada como garantía para el cumplimiento del contrato podrá ser ejecutada por la Administración.

En el derecho canadiense, las causales de rescisión de los contratos administrativos deberán estar debidamente contenidas dentro del clausulado del propio contrato; con la peculiaridad de que las causales no están reguladas en la LCOP (Quebec) ni en el RME (ámbito federal). Sin embargo, en los Cahier des charges et devis généraux se establecen causales de rescisión específicas dependiendo del tipo de contrato; adicionalmente, deberán estar contenidas en las cláusulas. Por supuesto, si fuese el caso, el contratista podrá solicitar la indemnización correspondiente y exigir el pago por los trabajos efectivamente realizados.

No se debe perder de vista que el contrato administrativo (en el derecho canadiense), esencialmente, no difiere de un contrato de derecho privado, por lo que el contrato en sí, como se ha insistido a lo largo de este trabajo, es una verdadera lex inter partes y, por ende, las causales de rescisión deberán estar contenidas en el clausulado del contrato, pues es finalmente la norma que debe ser aplicada al caso concreto.

En todo caso, la rescisión por parte de la autoridad deberá estar soportada por una cláusula contenida en el contrato y debidamente justificada la decisión de la autoridad ${ }^{68}$.

\section{GLOBALIZACIÓN, DERECHO COMPARADO Y SISTEMAS MIXTOS}

Con el fin de lograr el objetivo aquí planteado, es importante detenerse un poco en la explicación en cuanto a los efectos de la globalización en el derecho, sobre la necesidad del ejercicio comparatista y, por supuesto, sobre las implicaciones que tiene en los sistemas mixtos, o por lo menos, los estándares de diálogo que se requieren para entender mejor la institución jurídica que se viene tratando.

Más allá de lo mucho que se pueda discutir en relación con el tema de la globalización, desde sus primeras implicaciones, así como la falta de precisión en sus manifestaciones ${ }^{69}$, la realidad es que hoy en día el acceso a la información de todo el mundo es prácticamente instantáneo; ya no es necesario

67 Cfr. art. 60, párr. segundo LOPSRM.

68 Cfr. Garant. Droit administratif, cit., 434-435.

69 Cfr. Beck, U. ¿Qué es la globalización? Barcelona: Paidós, 1998, 53 ss. 
que dos personas se reúnan físicamente para realizar un negocio, y por ende las relaciones jurídicas se ven afectadas. Casanovas Esquivel, siguiendo a Twinning, señala que, respecto del ámbito del derecho, la globalización:

a) Desafía las teorías que conciben a los Estados Nación y a los sistemas jurídicos como entidades cerradas e impermeables.

b) Desafía la teoría de que el estudio del Derecho se puede circunscribir a dos tipos de ordenamientos: el derecho estatal y el derecho internacional público.

c) Desafía la suficiencia y validez del marco y el vocabulario conceptuales del marco jurídico ${ }^{70}$.

Aun cuando resulta imposible profundizar acá en este punto, lo dicho evidencia que las distintas influencias que se tienen hoy en día en virtud del tráfico jurídico existente, más allá de los derechos más tradicionales, como el internacional público y el internacional privado, generan un verdadero fenómeno, no solo de tráfico jurídico con nuevas exigencias regulatorias, sino de trasplantes jurídicos y de adaptaciones o "tropicalizaciones" de diversas instituciones jurídicas que no son propias del derecho interno, mejor dicho, que son tomadas de sistemas jurídicos diferentes del nuestro. Aun cuando, en principio, es necesario que las instituciones jurídicas, para que funcionen, surjan de la propia idiosincrasia y necesidades de cada Estado, la realidad es que esto no ocurre así. La aparición de estandarizaciones internacionales, como las normas y directrices de derecho suave emitidas por la Organización y Cooperación para el Desarrollo Económico (OCDE) o las circulares emitidas por el Banco Mundial y el Fondo Monetario Internacional, es un claro ejemplo de que existe una tendencia a homologar una serie de instituciones jurídicas; y, aun cuando dicha homologación no resultase posible in extremis, se tienen que desarrollar los puentes de diálogo necesarios para ello.

Al comienzo del presente trabajo se recordó que la Convención de las Naciones Unidas contra la Corrupción establece una serie de estándares para los contratos administrativos, con total y absoluta independencia del entendimiento que cada sistema jurídico tenga al respecto; es decir, sin importar si se trata de un contrato administrativo en un régimen del common law, donde la voluntad de las partes se privilegia por encima del sometimiento a la ley, o propia de la visión francesa de estos contratos, donde dichos estándares tienen que cumplirse y funcionar. En pocas palabras, no es tan importante

70 Casanovas Esquivel, J. A. Derecho comparado y cine. Estudio sobre el cine como recurso pedagógico para la enseñanza del derecho comparado. Tesis doctoral, Universidad Panamericana, Campus México. México, 2017, 17. 
la regulación que se siga, sino el objetivo que se persigue, el cual es, esencialmente, es el mismo.

Los trasplantes jurídicos son piezas fundamentales para la construcción y evolución del derecho en el mundo ${ }^{71}$. Baste con señalar que, en términos generales, la construcción del derecho administrativo mexicano está tomada en gran medida de instituciones del derecho francés, y que se han adoptado muchas formas propias del derecho español. En contraposición, el derecho canadiense toma la mayoría de sus instituciones del derecho británico, excepto en la provincia de Quebec, donde la mayor influencia es el derecho francés, si bien, en su coexistencia, uno y otro sistema han influido mutuamente en su evolución y desarrollo.

Los trasplantes jurídicos son una realidad, a propósito de lo cual señala Mota $\operatorname{Prado}^{72}$ que los sistemas jurídicos, aun tan diversos como el common law y el civil law, tienden cada vez más a parecerse, pues este fenómeno, por lo menos en América Latina (en casos como el brasileño y el mexicano), ha tomado en gran medida el modelo norteamericano de agencia regulatoria independiente; así en México, a partir de la creación con rango constitucional de los órganos constitucionales autónomos ${ }^{73}$. Si bien, en cuanto a su efectividad, el éxito del trasplante dependerá de la forma en que sea acogido por el sistema jurídico preexistente, teniendo el sistema la capacidad de adaptar e incorporar a la nueva institución; o bien, por el contrario, de producir su rechazo a partir de criterios jurisprudenciales.

Ante el desarrollo jurídico, sea en un sistema o en otro, y para efectos de este artículo, con referencia únicamente al tema de la contratación pública, resulta indispensable conocer las instituciones jurídicas a partir de la visión que los diversos sistemas jurídicos tengan al respecto, máxime porque, en el caso de México y Canadá, ambos países son socios comerciales en virtud del TLCAN, lo que también tiene efectos sobre los contratos administrativos que se celebran. Entre otras cosas, la legislación mexicana autoriza la participación de empresas extranjeras y brinda ciertas facilidades cuando esta relación se presenta en el marco de un tratado comercial ${ }^{74}$. Independientemente del campo en el que ejerza un jurista (sea el académico o el de consultoría), hoy en día

71 Cfr. Bonilla, D. Teoría del derecho y trasplante jurídicos: la estructura del debate. En BonILla, D. (ed.), Teoría del derecho y trasplantes jurídicos. Bogotá: Siglo del Hombre Editores y Universidad de los Andes, 2009, 11.

72 Cfr. Mota Prado, M. Presidential Dominance from a Comparative Prespective: The Relationship between the Executive Branch and Regulatory Agencies in Brazil. En Rose-ACKERMAN, S. y Lindseth, P. L, (eds.). Comparative Administrative Law. Stockport: Edward Elgar, 2011. Disponible en: http://ssrn.com/abstract=1690815 (Consultado el 3 de marzo de 2017).

73 No viene al caso discutir en este punto la diferencia entre órgano y organismo, pues parecería que para el legislador mexicano son términos completamente similares, de lo que es un buen ejemplo el tratamiento indistinto del Instituto Federal de Telecomunicaciones, la Comisión Nacional de Hidrocarburos y la Comisión Reguladora de Energía.

74 Cfr. arts. 14 LAASSP, 30, fracc. II LOPSRM y 6 LAPP. 
es indispensable concebir al derecho no exclusivamente desde una posición nacional, sino teniendo la mente abierta a otras realidades jurídicas de los más diversos orígenes ${ }^{75}$. En palabras de Pérez Luño:

El nuevo orden mundial de una sociedad interconectada y globalizada invita a contemplar los sistemas de fuentes del Derecho desde una perspectiva universalista $[\ldots][\mathrm{L}]$ os ciudadanos y juristas del siglo XxI deben ser conscientes de esa superación del marco territorial de los Estados nacionales, en lo que atañe al significado y operatividad de los sistemas normativos [...] Los esquemas rígidos de interpretación de las fuentes, basados en la soberanía estatal, en las fronteras nacionales y en compartimentos explicativos cerrados, son del todo inadecuados e insuficientes para captar los problemas de nuestro tiempo ${ }^{76}$.

Por su parte, Javier Barnés, profesor de Huelva, señala que el ejercicio del derecho administrativo comparado tiene un alcance global, lo cual se advierte en el ejercicio cotidiano del derecho, sea en la función pública, en los legisladores y en los tribunales en el momento de dictar sus fallos, además de su ejercicio en el seno de los organismos trasnacionales, teniendo como finalidad común (con total independencia de los objetivos que en cada caso se persiguen) la obtención de nuevos conocimientos ${ }^{77}$.

Pese a lo anterior, el ejercicio comparatista no resulta fácil en materia de contratos administrativos. Al respecto señala Boughey:

Existen [...] inconsistencias entre jurisdicciones relativas a la cuestión de si el derecho administrativo afecta también a los contratos del gobierno. [...] La mayoría de las jurisdicciones del common law tratan a los contratos celebrados por el gobierno de la misma forma que los contratos privados, atendiéndolos con los principios propios del derecho contractual. En contraste, en varias jurisdicciones de civil law, incluyendo la francesa y la española, muchos de los contratos celebrados por los organismos públicos se distinguen de los contratos celebrados entre particulares, y son sujetos de la jurisdicción administrativa, bajo las reglas del derecho administrativo. Sin embargo, otras tradiciones civilistas, como la holandesa y, hasta hace poco tiempo, la alemana, teóricamente tratan a los contratos celebrados por el gobierno como contratos de derecho privado, pero sometidos a reglas especiales sobre ciertas categorías de contratos. Auby argumenta que la

75 Cfr. Foster, N. H. D. The Journal of Comparative Law: A New Scholary Resource. En The Journal of Comparative Law. Vol. 1, n. ${ }^{\circ}$ 1, 2006, 1-12.

76 Pérez LuÑo, A. E. El desbordamiento de las fuentes del derecho. Madrid: La Ley, 2011, 100-101.

77 BARNÉs, J. Sobre el método del análisis comparado en el derecho administrativo: el caso del procedimiento y de la justicia administrativa. Disponible en: https://www.researchgate.net/ publication/294932866_SOBRE_EL_METODO_DEL_ANALISIS_COMPARADO_EN_EL_DERECHO_ADMINISTRATIVO_EL_CASO_DEL_PROCEDIMIIENTO_Y_DE_LA_JUSTICIA_ADMINISTRATIVA_en_prensa (Consultado el 3 de marzo de 2017). 
forma en que cada sistema legal define los límites entre el derecho contractual y el derecho administrativo "está directamente relacionada con el modo en que el sistema asume la división entre derecho público y derecho privado"78.

No está de más recordar acá que el argentino Cassagne ${ }^{79}$ sostiene que no es posible conducir los contratos que celebra el Estado a una categoría unívoca, que permita hacer un divorcio real entre la doctrina del derecho privado y la doctrina del derecho público.

En el derecho mexicano, la contratación pública se ha entendido como un instrumento que le permite al Estado la eficiencia en sus finanzas públicas, distribuyendo el gasto, asegurando las mejores condiciones en sus adquisiciones, e incluso como una forma de participar de la vida económica, convirtiéndose en un nuevo componente del mercado, que permite la activación económica de algunos sectores, fomentando la participación ciudadana, y a la vez satisfaciendo necesidades de carácter colectivo.

Para el derecho canadiense, los contratos administrativos resultan ser una categoría híbrida, aunque se establece que se regulan, por decirlo de alguna manera, en cuanto al contenido obligacional, por el CCQ; sin embargo, cuentan con una serie de disposiciones de derecho público, contenidas en la LCOP y el RME, que impiden determinar si el régimen canadiense está inclinado al derecho público o al derecho privado.

Si bien es cierto se ha sostenido, a lo largo de este trabajo, que la contratación administrativa en México sigue el modelo francés, donde el sometimiento a la ley sustituye a la autonomía de la voluntad prototípica de las relaciones jurídicas de derecho privado, también es importante subrayar que, dentro del sector energético, la contratación del Estado, a partir de las estructuras administrativas denominadas EPE, ha cambiado radicalmente; y de hecho, bien cabría afirmar que se trata de un modelo mixto de contratación, mucho más cercano al existente en países como Canadá (aunque en gran medida inspirado en el modelo anglosajón de government by contract).

\section{CONCLUSIONES}

A lo largo de este trabajo la pretensión fue mostrar un vis-à-vis entre dos regímenes contractuales aparentemente opuestos, el mexicano y el canadiense. El primero de ellos, seguidor de la tradición francesa de los contratos administrativos, mientras que el segundo hunde sus raíces en el derecho británico.

78 Boughey, J. Administrative Law: The Next Frontier for Comparative Law. En International and Comparative Law Quarterly. N. 62 (1), 2013, 69-70. Dor: https://doi.org/10.1017/ S0020589312000553

79 Cfr. Cassagne, J. C. El contrato administrativo. 3. a ed. Buenos Aires: Abeledo Perrot, 2009,5 ss. 
Los contratos administrativos en México, en principio, se hallan fuertemente regulados por la legislación y por el sometimiento de la Administración a la ley; en Canadá, prima la autonomía de la voluntad para contratar, prácticamente no haciendo ningún tipo de distinción entre el contrato privado y el contrato administrativo.

No deja de llamar la atención que tanto en el caso mexicano como en el canadiense, la jurisprudencia ha establecido en el interior de su regulación reglas y principios similares, a pesar de ser sistemas jurídicos tan diferentes. Sin embargo, los hacen coexistir sin mayores problemas, como parte de su proceso de evolución natural; parecería que en los países que siguen la tradición romano-canónica, cada vez se recurre más a instrumentos del derecho anglosajón, y a la inversa, estos últimos cada vez más se apoyan en legislación propia del civil law.

Esto, sin duda, no está exento de problemas, tan simples como el referido al entendimiento de las instituciones jurídicas que bajo cada sistema se tiene. Sin embargo, no se debe perder de vista que los objetivos son los mismos, aunque las palabras sean distintas, y esto en gran medida no es más que otra manifestación de la globalización jurídica que se vive hoy en día. En efecto, se ha convertido en una verdadera necesidad para el jurista contemporáneo, en cualquiera de sus facetas, no estar cerrado a su propio derecho nacional, ni siquiera a su propio sistema jurídico, resultándole imperioso, en todas las áreas del ejercicio de la profesión, conocer el derecho de los otros.

Al final, este documento ha intentado conocer más diferentes sistemas en cuanto a la contratación administrativa, con el fin de aprender, crecer, adaptar y hacer evolucionar la ciencia jurídica, tomando en cuenta que siempre son necesarios los ejercicios comparatistas ante un nuevo escenario de un derecho más universal.

\section{REFERENCIA}

AA.vv. Enciclopedia Jurídica Mexicana. T. VI. México: IIJ-UnAm/Porrúa, 2002.

Acosta Romero, M. Compendio de derecho administrativo. Parte general. México: Porrúa, 1996.

BЕск, U. ¿Qué es la globalización? Barcelona: Paidós, 1998.

Bonilla Maldonado, D. Teoría del derecho y trasplante jurídicos: la estructura del debate. En Bonilla Maldonado, D. (ed.), Teoría del derecho y trasplantes jurídicos. Bogotá: Siglo del Hombre Editores y Universidad de los Andes, 2009.

Boughey, J. Administrative Law: The Next Frontier for Comparative Law. En International and Comparative Law Quarterly. N. ${ }^{\circ}$ 62, 2013. 
Casanovas Esquivel, J. A. Derecho comparado y cine. Estudio sobre el cine como recurso pedagógico para la enseñanza del derecho comparado. Tesis doctoral, Universidad Panamericana, Campus México. México, 2017.

Cassagne, J. C. El contrato administrativo. 3. ${ }^{a}$ ed. Buenos Aires: Abeledo Perrot, 2009.

Delgadillo Gutiérrez, L. H. y Lucero Espinosa, M. Compendio de derecho administrativo.

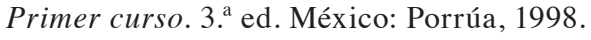

Díez, M. M. Manual de derecho administrativo. 4. a ed. Buenos Aires: Plus Ultra, 1985.

Foster, N. H. D. The Journal of Comparative Law: A New Scholary Resource. En The Journal of Comparative Law. Vol. 1, n. ${ }^{\circ}$ 1, 2006.

Galindo Camacho, M. Derecho administrativo II. México: Porrúa, 1996.

Gamero Casado, E. y Fernández Ramos, S. Manual básico de derecho administrativo. Madrid: Tecnos, 2008.

Garant, P. Droit administratif. 6. ${ }^{\mathrm{a}}$ ed. Cowansville: Éditions Yvon Blais, 2010.

Greve, C. y Ejersbo, N. Contracts as Reinvented Institutions in the Public Sector: CrosCultural Comparison. Westport: Praeger, 2005.

JurisClasseur Québec. Droit administratif. Montréal: LexisNexis, 2016.

Lombard, M. y Dumont, G. Droit administratif. 8. a ed. Paris: Dalloz, 2009.

López Olvera, M. A. La instancia administrativa. Problemas actuales de la justicia administrativa. Principios y fuentes del proceso administrativo. Órgano y procedimientos judiciales. Buenos Aires: Ediar, 2008.

López-Elías, J. P. Aspectos jurídicos de la licitación pública en México. México: IIJUNAM, 1999.

Lucero Espinosa, M. La licitación pública. 2. ${ }^{a}$ ed. México: Porrúa, 2002.

Molot, H. L. The Carltona Doctrine and the Recent Amendments to the Interpretation Act. En Ottawa Law Review. Vol. 26, n. ${ }^{\circ}$ 2, 1994.

Morand-Deviller, J. Droit administratif. 12. . ed. Paris: Montchrestien Lextenso éditions, 2011.

Noguellou, R. y Stelkens, U. (eds.). Droit comparé des contrats publics. Bruxelles: Bruylant, 2010.

Parada, R. Derecho administrativo I. Parte general. 13. a ed. Madrid: Marcial Pons, 2002.

Pérez Luño, A. E. El desbordamiento de las fuentes del derecho. Madrid: La Ley, 2011.

Rodríguez-Arana Muñoz, J. La vuelta al derecho administrativo (A vueltas con lo privado y lo público). En Revista de Derecho, Universidad de Montevideo. Año IV, n. ${ }^{\circ}$ 7, 2005.

Rose-Ackerman, S. y Lindseth, P. L. (eds.). Comparative Administrative Law. Stockport: Edward Elgar, 2011. 
Santofimio Gamboa, J. O. y BéJar Rivera, L. J. Las concesiones públicas. Fundamentación teórica. México: Novum, 2014.

TAggart, M. (ed.). The Province of Administrative Law. Oxford: Hart Publishing, 1997.

\section{Legislación}

Code Civil du Québec.

Constitución Política de los Estados Unidos Mexicanos.

Ley de Adquisiciones, Arrendamientos y Servicios del Sector Público.

Ley de Asociaciones Público Privadas.

Ley de Obras Públicas y Servicios Relacionados con las Mismas.

Loi sur les contrats des organismes publics.

Règlement sur les marchés de l'État.

Ley de Hidrocarburos.

Ley de la Industria Eléctrica.

\section{Internet}

http://collections.banq.qc.ca/ark:/52327/bs2748781

http://papers.ssrn.com

http://revistaderecho.um.edu.uy

http://scj.scjn.gob.mx

http://www.canlii.org

http://www.researchgate.net

http://www.scc-csc.ca/home-accueil/index-eng.aspx

http://www.vgso.vic.gov.au/sites/default/files/Managing\%20Government\%20Contracts\%20 July\%202010.pdf 